\title{
Show de Projetos: Recurso Educacional para o Ensino de Projetos
}

\author{
Gustavo O. Andrade ${ }^{1}$, Márcia M. Silva ${ }^{1}$, Nelson Coelho Jr. ${ }^{2}$, Cleonice W. S. Oliveira ${ }^{1}$ \\ ${ }^{1}$ Universidade Federal Fluminense (UFF), ${ }^{2}$ Universidade Presbiteriana Mackenzie \\ andrade.oliveira@gmail.com, marcia_maximiano@hotmail.com,\{nelsoncj18, cleowebersouza\}@gmail.com
}

Palavras-chave: Jogos, Gerenciamento de Projetos, Show de Projetos

Introdução. A informática, manifestada pelo uso das Tecnologias da Informação e Comunicação (TIC) está presente em praticamente todas as áreas. No setor educacional, por exemplo, a prática pedagógica está arquitetada como processo articulador, de forma a manifestar interesse comum tanto para docentes como discentes em suas trajetórias de aprendizagem. A disciplina Gerenciamento de Projetos por ser densa e extremamente importante [1], tanto nas universidades, quanto nas empresas, devido ao seu uso contínuo em diferentes situações. Várias estratégias para ensinála têm sido colocadas em prática, tais como: e-Learning (aprendizagem eletrônica), EaD (educação a distância), jogos, ilustrações, áudio, dinâmicas, dentre outros. Dessas aprendizagens, os jogos [2, 3] são excelentes meios de buscar um fluxo otimizado de informações e padrões a serem seguidos, quando aplicados de forma lúdica, nas instituições, inclusive nas acadêmicas, pois os alunos estão adquirindo conhecimento de uma forma divertida e interativa. Portanto, este trabalho tem como objetivo investigar a utilização de jogos como instrumentos de aprendizagem na educação, em especial, no ensino de Gerenciamento de Projetos. Motivação. A sustentação metodológica da pesquisa caracterizou-se como sendo uma abordagem qualitativa com análise complementar de dados quantitativos, e quanto aos objetivos, exploratória. A pesquisa teve amostra de especialistas e/ou conhecedores em Gerenciamento de Projetos de um grupo específico do Whatsapp que trata de assuntos pertinentes ao tema. Para coletar os dados, um questionário online foi adaptado. Para atender aos objetivos propostos, estabeleceram-se procedimentos metodológicos distribuídos nas seguintes etapas: (1) Criação do jogo Show de Projetos para especialistas e/ou conhecedores de Gerenciamento de Projetos; (2) elaboração de um instrumento para coletar os dados (questionário); (3) disponibilização do jogo Show de Projetos para os especialistas e/ou conhecedores de Gerenciamento de Projetos para ser jogado e testado por eles; (4) coleta da opinião dos especialistas e/ou conhecedores de Gerenciamento de Projetos em relação ao jogo experimentado e, por último, (5) Análise desses resultados. [4]. Resultados. De um total de 60 questionários enviados teve-se retorno de 10 questionários respondidos, dos quais 44,4\% dos participantes disseram ter bom conhecimento sobre o tema Gerenciamento de Projetos, 22,2\% consideram especialistas no assunto, 22,2\% declararam serem portadores de conhecimento mediano e, apenas 11,1\% consideram possuir pouco ou nenhum conhecimento nas questões tratadas pelo jogo. Em relação ao conteúdo ser bem organizado e fácil de entender, 44,4\% dos pesquisados concordam que é organizado e fácil para entender. 22,2\% declararam que não encontraram dificuldade; 22,2\% ficaram indecisos ao responder. 11,1\% dos pesquisados não concordam que o jogo é bem organizado e fácil de entender. Quando perguntado se o jogo educacional facilita a construção de conhecimento e habilidades envolvendo conceitos de Gerenciamento de Projetos, 33,3\% dos respondentes disseram que, de fato, o jogo educacional proporciona a construção do conhecimento, 55,6\% da amostra também concordaram de forma discreta. Todavia, 11,1\% dos entrevistados, discordam de tal afirmação. Para a pergunta se os meios utilizados para apresentar as informações no software educacional aumentam a compreensão do conteúdo, 66,7\% concordam que, consideravelmente, aumentam. 22,2\% concordam, mais plenamente, que sim. Já $11,1 \%$ da amostra discordam que o jogo aumenta a compreensão do conteúdo. Quanto à interrogação sobre o jogo educacional ser apropriado para os estudos: 55,6\% dos pesquisados disseram que sim; enquanto $44,4 \%$ responderam que é extremamente apropriado para os estudos. Discussão. Para jogar, é necessário entender sobre conceitos de Gerenciamento de Projetos para assim, então, atingir o objeto final que é ser um profissional da área. Notase que jogos educativos são relevantes para a construção do saber e corroboram para a relevância deste trabalho, com respostas sobre: a contribuição para a construção de habilidades, 55,6\%, a facilidade de assimilação de conceitos, 44,4\%. As questões básicas do aplicativo facilitam à interação do conteúdo e a prática de ensino, com isso melhora o desempenho do aprendizado. A interação em diferentes níveis e o entusiasmo proporcionado pelo jogar são visíveis na tela e nas funções básicas da execução dos mesmos. Esses resultados iniciais ainda não são conclusivos uma vez que a amostra obtida é muito pequena. Portanto, uma nova aplicação do jogo, com uma amostra maior, deverá ser realizada para que, assim, haja uma consistência melhor dos resultados esperados. Conclusões. Dentro da visão de gestão de projetos, o jogo Show de Projetos foi concebido para auxiliar no ensino e no aprendizado, e inspirado para melhorar o desempenho do ensino aprendizagem. A ideia inicial do jogo é permitir ao participante adquirir conhecimento, desenvolver habilidades e avaliar atitudes articulando, dessa forma, as dimensões cognitiva, afetiva e comportamental em uma situação de aprendizagem caracterizada por alto nível de envolvimento ativo. Neste sentido, os jogos são excelentes meios para buscar um fluxo otimizado de informações e padrões a serem seguidos, quando aplicados de forma lúdica, nas instituições, inclusive nas acadêmicas, pois, os alunos podem adquirir conhecimento de uma forma divertida e interativa.

\section{Bibliografia}

[1] Codas, M. M. B. (1987) Gerência de projetos - uma reflexão histórica. Revista de Administração de Empresas 27(1): 33-37. DOI: 10.1590/S0034-75901987000100004

[2] Mattar, J. (2009) Games em educação - como os nativos digitais aprendem. São Paulo: Pearson.

[3] Rodrigues, G. C. F. S. (2014) Instrumento para Avaliação de Jogos Eletrônicos Educativos do Ensino Fundamental I. Dissertação. Mestrado Profissional em Linguística e Ensino. 123p. Universidade Federal da Paraíba.

[4] Oliveira, A.R.A. (2014) Questionário para Avaliação de Sistema de Software Educacionais no Apoio do Processo de Ensinoaprendizagem em Gerência de Projetos de Software. Monografia. Bach. Sistemas de Informação, 118 p. Univ. Federal de Lavras. 